\title{
Oxidative Stress in Humans Training in a Cold, Moderate Altitude Environment and Their Response to a Phytochemical Antioxidant Supplement
}

\author{
Matthew C. Schmidt, MS; E. W. Askew, PhD; Donald E. Roberts, PhD; Ronald L. Prior, PhD; W. Y. Ensign Jr, \\ $\mathrm{PhD}$; Robert E. Hesslink Jr, PhD \\ From the University of Utah, Salt Lake City, UT 84112 (Drs Schmidt and Askew), the Naval Health Research Center, San Diego, CA (Drs \\ Ensign and Roberts), the USDA, ARS Arkansas Children's Nutrition Center, Little Rock, AR (Dr Prior), and Natural Alternatives \\ International, San Marcos, CA (Dr Hesslink).
}

\begin{abstract}
Objective.-This study examined the effectiveness of an antioxidant mixture containing vitamin E, $\beta$-carotene, ascorbic acid, selenium, $\alpha$-lipoic acid, $N$-acetyl 1-cysteine, catechin, lutein, and lycopene to reduce oxidative stress in US Marines undergoing 24 days of cold-weather field training at a moderate altitude.

Methods.-Forty physically active male volunteers (ages 18-40) were randomly assigned to a treatment (antioxidant) group $(n=21)$ or a control (placebo) group $(n=19)$. Breath pentane (BP), serum lipid hydroperoxides (LPO), urine malondialdehyde (MDA), urine 8-hydroxy deoxyguanosine (8-OHdG), ferric-reducing ability of plasma (FRAP), and serum and urine oxygen radical absorption capacity (ORAC) were measured as indicators of oxidative stress and antioxidant status. Urine was sampled at days 0,12 , and 24. Serum and breath were sampled on days 0 and 24.

Results.-Both groups exhibited increased levels of oxidative stress after 24 days of field training, as indicated by an increased LPO, pentane, and 8-OHdG. There was no significant difference between the treatment and placebo groups at day 24; however, there was some indication that test subjects with initially low antioxidant capacity (ORAC) may have benefited from the antioxidant supplement.

Conclusions.-An increased level of oxidative stress was associated with high levels of physical exertion of training in a cold environment at moderate altitude. The antioxidant mixture tested did not attenuate the mean oxidative stress levels in the entire group of test subjects, but it may have reduced the oxidative stress of some individuals with low initial antioxidant status.
\end{abstract}

Key words: oxidative stress, altitude, antioxidants, phytochemicals, exercise, vitamin E, $\beta$-carotene, ascorbic acid, 8-hydroxy deoxyguanosine, pentane, malondialdehyde, oxygen radical absorption capacity, ferric-reducing ability of plasma, lipid hydroperoxides

\section{Introduction}

Oxidative stress is the term used to indicate the presence of increased levels of reactive oxygen species (ROS). This occurs when the body's own natural and dietary antioxidant defense systems are not capable of quenching the excess free radicals or ROS generated. Left uncontrolled, the formation of ROS can lead to tissue oxidative damage and can cause oxidative damage to var-

Corresponding author: Wayne Askew, $\mathrm{PhD}, 250 \mathrm{~S} 1850$ East, HPR N-239, Division of Foods and Nutrition, University of Utah, Salt Lake City, UT 84112 (e-mail: wayne.askew@health.utah.edu). ious biologic macromolecules, such as proteins, nucleic acids, lipids, and lipoproteins. ${ }^{1-6}$ The inability to completely limit the effect of ROS may ultimately be linked to the incidence of such chronic diseases as cancer, inflammation, aging, atherosclerosis, degenerative eye disease, and Parkinson's disease. ${ }^{2,4,7-9}$

The formation of ROS also occurs as a result of endogenous and exogenous conditions. Some of these exogenous sources are ultraviolet light, anoxia, pollutants, inflammation, smoking, and radiation. ${ }^{5,10-14}$ Endogenous sources include direct reduction of molecular oxygen, reduced nicotinamide-adenine dinucleotide phos- 
phate oxidase, phagocytic cells, D-amino acid oxidases, xanthine oxidase, epinephrine, coenzyme Q10, vitamin $\mathrm{K}$, and the cytochrome P450 system. ${ }^{1-5}$

Leakage of electrons from the mitochondrial respiratory chain to yield the superoxide anion $\left(\mathrm{O}_{2}{ }^{-}\right)$occurs continuously during normal aerobic metabolism. Most oxygen consumed will be reduced to water; however, up to $4 \%$ to $5 \%$ of the oxygen consumed can directly reduce molecular oxygen to form superoxides as electrons escape the respiratory chain. ${ }^{5}$ During aerobic exercise, oxygen uptake by skeletal muscle can be increased 10 to 15 times its normal rate. ${ }^{15,16}$ As the rate of consumption of oxygen and mitochondrial oxidative activity increases, so does the rate of electron leakage. ${ }^{1}$ Other probable mechanisms of ROS formation during exercise are reperfusion of ischemic tissue with oxygen-rich blood, xanthine oxidase, respiratory burst of polymorphonuclear leucocytes, and interaction with reactive nitrogen intermediates. ${ }^{11}$ The potential for oxidative stress is increased after acute strenuous exercise. ${ }^{7,15,16}$ The symptoms of exercise-induced oxidative injury include muscle soreness, fatigue, and increased recovery time. ${ }^{16}$ Ultraviolet light can be hazardous to humans and other organisms by inducing cell death, inflammation, immunosuppression, and even initiation of certain skin cancers. ${ }^{17,18}$ Ultraviolet light can foster the release of a singlet molecular $\left({ }^{1} \mathrm{O}_{2}\right)$ and $\mathrm{O}_{2}{ }^{--}$radicals that may attack unsaturated fatty acids in membranes to remove an electron (hydrogen ion). This removal of hydrogen can induce lipid peroxidation (LPO) and cause oxidative injury to the area exposed to intense sunlight. Ultravioletinduced free radical generation within the cell can also damage DNA and suppress its synthesis. ${ }^{1,11}$

Certain environments may lead to increased levels of oxidative stress $^{19}$; for example, oxidative stress, because of multiple stressors, may be greater at moderate to high elevations than at sea level. ${ }^{20-24}$ Moderate altitude and high altitude can arbitrarily be defined between 5000 and $10000 \mathrm{ft}(1524-3048 \mathrm{~m})$ and $>10000 \mathrm{ft}$ or $3050 \mathrm{~m}$ elevation, respectively. Simon-Schnass ${ }^{24}$ found that climbing to high elevation $(\sim 4600 \mathrm{~m})$ approximately doubled LPO (breath pentane [BP]). Vasankari et a ${ }^{25}$ examined the effects of endurance exercise at moderate altitude $(1650 \mathrm{~m})$ on oxidative stress by assessment of LPO (serum diene conjugation). In 9 male skiers who raced $(20-30 \mathrm{~km})$ at sea level and then at moderate altitude, it was found that at moderate altitude, serum diene conjugation was significantly higher both before $(25 \%)$ and after $(30 \%)$ the race than at sea level. These findings suggest that the level of oxidative stress may be greater at moderate altitudes when living, training, and racing, although short periods of ski training at altitude have not been associated with significantly elevated lev- els of oxidative stress. ${ }^{26}$ Some of the possible explanations for the increased formation of ROS are increased intensity of ultraviolet light, increased metabolic rate, fluctuating temperatures, and hypoxia. 7,14,19

Aerobic organisms have developed systems to limit the damage caused by ROS. Cells develop a range of mechanisms for intercepting or compartmentalizing ROS, but these defenses are not completely successful. ${ }^{27}$ Antioxidant defense systems can be classified as endogenous or dietary. Endogenous components include glutathione, selenium-glutathione peroxidase, ferric-catalase, nicotinamide-adenine dinucleotide phosphate, ubiquinol-10, manganese, copper, zinc-superoxide dismutase, uric acid, ferric iron, copper-binding proteins, and ferric-complex-binding proteins. ${ }^{11,12,15}$ Dietary antioxidants include tocopherols and tocotrienols, ascorbic acid, and vitamin A or its precursor, $\beta$-carotene. Several studies have been conducted on the effectiveness and properties of the dietary antioxidants vitamin E, A, and C and the dietary mineral selenium. It has been shown that deficiencies of these antioxidant vitamins can result in an increase in oxidative stress ${ }^{28-32}$ and that supplementation with these antioxidants lessens LPO. ${ }^{28,30}$

Plant-derived compounds, also called phytochemicals, have also demonstrated antioxidant capacities. Phytochemicals shown to offer additional antioxidant support include carotenoids, bioflavonoids, flavonoids, and others. ${ }^{28,33-41}$ Supplementing with vitamins, minerals, and phytochemicals known to have direct or indirect antioxidant characteristics may expand the body's natural and dietary defense systems against oxidative stress. These antioxidant defense systems should not be viewed as separate entities but rather as interdependent and synergistic. ${ }^{28}$ The synergistic properties of antioxidant compounds are not well understood. Several studies have shown that certain antioxidant mixtures were more effective in reducing oxidative stress than single antioxidants. ${ }^{21,31,42,43}$ Stahl et al ${ }^{42}$ examined different combinations of carotenoids and individual carotenoids for their protection of multilamellar liposomes against oxidative damage in vitro. They found that combinations of carotenoids were more effective than single compounds in preventing oxidative damage. Their different physicochemical properties and/or location in the biomembranes ${ }^{42,44}$ could possibly explain the synergistic properties of these carotenoids.

Pfeiffer et $\mathrm{al}^{20}$ studied US Marine Corps personnel participating in winter field training at the Winter Warfare Training Scenario at the US Marine Corps Mountain Warfare Training Center, Bridgeport, CA, as a model to investigate oxidative stress associated with intense physical exertion, ultraviolet light exposure, and fluctuating temperatures at moderate altitudes. A significant increase 
in oxidative stress at the end of a 14-day field-training period was noted. An antioxidant supplement consisting of a daily dose of $20000 \mathrm{IU} \beta$-carotene, $400 \mathrm{IU}$ vitamin E, $500 \mathrm{mg}$ vitamin C, $100 \mu \mathrm{g}$ selenium, and $30 \mathrm{mg}$ zinc was associated with some attenuation of oxidative stress indicators but did not reduce all oxidative stress indicator levels back to baseline values. Chao et $\mathrm{al}^{21}$ performed a follow-up study using the same test model to evaluate the capability of $\alpha$-tocopherol, ascorbic acid, and $\beta$-carotene ingested singly or as a mixture on the reduction of oxidative stress. They found that the mixture was more effective than the ingestion of single antioxidants or a placebo in reducing oxidative stress, as indicated by BP. Although the mixture of antioxidants was associated with a significant decrease in oxidative stress, it was not able to reduce the level of oxidative stress back to baseline.

To summarize, the use of conventional antioxidant supplements has shown some attenuation of oxidative stress indicators but has not reduced these indicator levels to baseline values. The purpose of our present study was to test an antioxidant supplement theorized to contain a more optimal or "synergistic" combination of antioxidants and phytochemicals utilizing the same test US Marine cold-weather moderate-altitude training model. It was theorized that a more optimal combination of antioxidants, such as that contained in a phytochemical antioxidant mixture, might be synergistic and hence more effective in attenuating oxidative stress associated with strenuous work in an outdoor environment.

\section{Methods}

\section{SUBJECTS}

Volunteers were from the US Marine Corps, 3rd Battalion of the 4th Marines stationed at the Marine Corps Air Ground Combat Center, 29 Palms, CA. These Marines were undergoing winter mountain operation training at the US Marine Corps Mountain Warfare Training Center. The purpose of this winter training was to prepare Marines for military operations in cold, harsh environments. The 24-day training included snowshoeing, bivouac formation, cross-country skiing, mountain patrolling, survival skills, avalanche searches, mountain navigation, and live-fire ambushes. The energy requirements of many of these activities are similar to civilian recreational activities and can probably be used as a general model for individuals undergoing strenuous work in cold environments at moderate altitudes. The first 3 days of training took place in the garrison $(2053 \mathrm{~m})$, where the Marines received briefings and training to prepare for their operations in the field, which ranged in elevation from 2546 to $2804 \mathrm{~m}$. During field training, the temperature ranged from $8^{\circ} \mathrm{F}\left(-13^{\circ} \mathrm{C}\right)$ to $49^{\circ} \mathrm{F}\left(9.4^{\circ} \mathrm{C}\right)$. The average low temperature was $19.5^{\circ} \mathrm{F}\left(-6.9^{\circ} \mathrm{C}\right)$, and the average high was $37.3^{\circ} \mathrm{F}\left(2.9^{\circ} \mathrm{C}\right)$. All field training took place in snow-covered areas.

Human use approval was obtained from the University of Utah Health Sciences Institutional Review Board and the Naval Health Research Center, San Diego. Forty male subjects completed the study. Test subjects were briefed on the purpose of the study, and they signed an informed consent agreement.

\section{SUPPLEMENT}

Subjects were randomly divided into 2 groups. The control group $(n=19)$ received a placebo, and the treatment group $(n=21)$ received the supplement. The antioxidant supplement contained $20050 \mathrm{IU} \beta$-carotene, $330 \mathrm{mg}$ ascorbic acid, $650 \mathrm{IU} \alpha-, \beta-, \gamma-$, and $\delta$-tocopherols, 167 $\mu \mathrm{g}$ selenium, $13.2 \mathrm{mg}$ catechin (green tea), $500 \mu \mathrm{g}$ lutein (Tagetes erecta), and $100 \mu \mathrm{g}$ lycopene (tomato), $181 \mathrm{mg}$ $\mathrm{N}$-acetyl 1-cysteine, and $5 \mathrm{mg}$ pomegranate extract. Additionally, $100 \mathrm{mg}$ of a vegetable blend concentrate supplying lutein, zeaxanthin, $\beta$-carotene, $\alpha$-carotene, and lycopene was added to the mixture. Two capsules were taken daily, one in the morning before breakfast and one before dinner. The supplement or the placebo was taken daily for a 24-day period. The test subjects consumed standard military field rations during this 24-day period. ${ }^{20,21}$

\section{MEASUREMENTS: BREATH, BLOOD, URINE, AND ANTHROPOMETRIC}

The study covered 24 days, and there were 3 data collection periods. On day 0 , subjects provided an overnight urine sample, a blood sample, and a breath sample. Blood samples were taken by venipuncture from the antecubital vein. Urine collection started after the evening meal and continued until the first void the following morning. Breath samples were collected between 8 and $10 \mathrm{AM}$. Anthropometric measurements (skinfold, height, and weight) were collected. Body composition was estimated from skinfold measurements using established equations. ${ }^{45}$ Skinfold calipers (Harpenden Caliper, Holland, MI) were used to measure skinfold thickness at the abdomen, thigh, and chest in 2 consecutive sets. Height was determined using a stadiometer. Subjects received their placebo or supplement and started taking them for the duration of the field training. On day 12, an overnight urine sample was collected. On day 24, the protocol of day 0 was repeated. 


\section{ANALYTICAL METHODS}

Two 10-mL samples of blood were obtained from each subject using clot-activating vacutainer tubes. After clotting over ice in subdued light, the samples were centrifuged at 2000 to $3000 \mathrm{rpm}$ for 10 minutes. Serum (2 $\mathrm{mL}$ ) was transferred into cryogenic tubes and frozen over dry ice. Samples were shipped to Genox Laboratories, Baltimore, MD, for analysis of LPO and carotenoid levels. Measurements of LPO were made by spectrophotometric assay performed on a robotic chemical analyzer. ${ }^{46}$ Concentration of carotenoids was measured using high-pressure liquid chromatography on a Hewlett-Packard (Palo Alto, CA) 1090 HPLC system monitoring $\alpha$-tocopherol at $292 \mathrm{~nm}$ and retinol at $320 \mathrm{~nm} .{ }^{47}$

An aliquot of serum was also shipped to the US Department of Agriculture Human Nutrition Center, Tufts University, Boston, MA, where antioxidant capacity was estimated using the oxygen radical absorption capacity (ORAC) and ferric-reducing ability of plasma (FRAP) assays. The ORAC and FRAP assays are both estimates of antioxidant capacity but differ in their ability to detect various antioxidant compounds. Values of ORAC were determined by fluorescence of the oxidized $\beta$-phycoerythrin indicator protein as described by Cao et al. ${ }^{48}$

The FRAP assay can be performed in either plasma or serum. In this study, FRAP was performed in serum to determine the antioxidant power of the serum samples. ${ }^{49}$ This assay (FRAP) was determined by the method of Benzie and Strain. ${ }^{49}$ The overnight urine collection was tested for specific gravity with a clinical refractometer (American Caduceus Industries Inc, Carle Place, $\mathrm{NY}$ ). Two $15-\mathrm{mL}$ samples were frozen and shipped to Genox for analysis for urine 8-hydroxy deoxyguanosine (8-OHdG), creatinine, and urine malondialdehyde (MDA). An aliquot of urine was also shipped to the US Department of Agriculture Human Nutrition Center, Tufts University, for an estimate of ORAC to see how well urine and serum antioxidant capacity estimates agreed with each other.

Urine 8-OHdG was determined using an enzymelinked immunosorbent assay (ELISA) monoclonal antibody kit (Genox). The ELISA monoclonal antibody assay is a competitive ELISA for quantitative measurement of 8 -OHdG. ${ }^{50}$ The optical density was measured at a wavelength of $492 \mathrm{~nm}$. The spectrophotometric assay was performed on a robotic immunochemical analyzer. $^{51}$

Urine MDA was determined by mixing $150 \mu \mathrm{L}$ of 12 $\mathrm{N} \mathrm{HCl}$ with the 200- $\mu \mathrm{L}$ sample in a closed test tube with a tight stopper. The test tube was allowed to incubate for 60 minutes at $45^{\circ} \mathrm{C}$ with thiobarbituric acid and was then cooled on ice. The thiobarbituric acid-MDA adduct was measured by absorption at $586 \mathrm{~nm}$. A standard curve was generated and used to measure MDA concentration in urine samples. ${ }^{52}$

Creatinine was measured by reacting the urine sample with picric acid under alkaline conditions to form a Janovski complex (red). The spectrophotometric assay was performed on a robotic immunochemical analyzer. ${ }^{53}$

Urine ORAC was determined in a manner similar to that of serum by measuring the fluorescence of the oxidized b-phycoerythrin indicator protein. ${ }^{48}$ To determine the ORAC values of urine, the reaction was allowed to go to competition. After the reaction reached completion, the area under the kinetic curve was integrated to a blank reaction containing antioxidant protection. The area under the curve is proportional to the concentration of all the antioxidants present in the sample. ${ }^{48}$

Breath samples were acquired from each volunteer using a commercial device that trapped and discarded the first $500 \mathrm{~mL}$ of expired air and then collected approximately $1000 \mathrm{~mL}$ of the subsequent deep alveolar air in a Tedlar bag (Norton Performance Plastics, Akron, OH). DataChem Laboratories (Salt Lake City, UT) analyzed $250 \mathrm{~mL}$ of the air sample for pentane. Measurements of BP were made by gas chromatography (Hewlett-Packard 5890 GC) with flame ionization detection (column, Chrompack PLOT-U $25 \mathrm{~m}$ by $0.32 \mathrm{~mm}$ internal diameter; detector, flame ionization detection at $220 \mathrm{C}$; air, 250 $\mathrm{kPa}$; hydrogen, $110 \mathrm{kPa}) .^{54}$

\section{STATISTICS}

Statistical analysis was performed using SPSS statistical program version 8.0 (SPSS Inc, Chicago, IL). To test the hypothesis for a treatment effect (for indices having more than 2 collection periods), a 2-way repeated-measures analysis of variance (ANOVA) was used. The test statistic of interest was the interaction term (time by group effect) of the model. A significant $P$ value $(P<$ $.05)$ for the interaction term was considered a demonstration of a treatment effect.

The difference between the 2 groups at different follow-up periods was of interest to ascertain if there was a time-dependent pattern. However, because none was found, a straightforward alternative approach was used. Pocock $^{55}$ suggests simply testing for the change from baseline to the endpoint, which may be of greatest importance. For the current study, change from time 0 to day 24 was deemed of greatest interest. The repeatedmeasures ANOVA was selected as the method for testing the treatment hypothesis. Secondary, using Pocock's suggestion, a day 24 change score (day 24 minus day 0 ) was computed, and the 2 groups' change scores were compared using an independent Student's $t$ test. The 
Table 1. Test subject characteristics, day 0 and day $24^{*}$

\begin{tabular}{|c|c|c|c|c|c|c|c|c|}
\hline Group & $\mathrm{n}$ & $\begin{array}{c}\text { Age } \\
(y)\end{array}$ & $\begin{array}{c}\text { Day } 0 \\
\text { body weight } \\
(\mathrm{kg})\end{array}$ & $\begin{array}{c}\text { Day } 24 \\
\text { body weight } \\
(\mathrm{kg})\end{array}$ & $\begin{array}{c}\text { Day } 0 \\
\text { body fat } \\
(\%)\end{array}$ & $\begin{array}{c}\text { Day } 24 \\
\text { body fat } \\
(\%)\end{array}$ & $\begin{array}{c}\text { Day } 0 \\
\text { body water } \\
(\%)\end{array}$ & $\begin{array}{c}\text { Day } 24 \\
\text { body water } \\
(\%)\end{array}$ \\
\hline Control & 19 & $22.9 \pm 5.1$ & $82.3 \pm 8.7$ & $77.7 \pm 8.2$ & $14.8 \pm 4.4$ & $12.6 \pm 4.4$ & $61.2 \pm 5.0$ & $62.8 \pm 4.9$ \\
\hline Treatment & 21 & $22.5 \pm 3.9$ & $80.0 \pm 11.3$ & $74.2 \pm 10.9$ & $11.5 \pm 5.6$ & $9.9 \pm 4.9$ & $64.2 \pm 5.4$ & $65.9 \pm 5.1$ \\
\hline
\end{tabular}

*Means $\pm \mathrm{SD}$.

change from baseline to day 24 was considered the most important; this comparison provided a check of the reasonableness of the repeated-measures ANOVA. The repeated-measures ANOVA, change score $t$ tests, and paired $t$ tests all supported the same conclusions.

As an exploratory analysis, change scores were computed from baseline to each repeated measurement, and study group differences (treatment vs control) were tested for each of these 6 possible change scores using an independent group's $t$ test. Although the actual $P$ values from these statistical tests are reported, conclusions are based on a Bonferroni multiple-comparison correction $(P \leq$ alpha divided by number of tests; ie, $P \leq .05 / 3=$ $.02)$.

The purpose for using change scores was to control for baseline differences (significant or not) between the control and treatment groups. The repeated-measures ANOVA and the independent group's $t$ test on the change scores both controlled for initial baseline group differences.

For the variables that were collected only at baseline and day 24, an independent $t$ test on the change scores was used in place of the repeated-measures ANOVA. This is a consistent approach, since an independent $t$ test on the change score gives a $P$ value that is identical to the interaction term of the repeated-measures ANOVA. Paired $t$ tests were used to test for a significant difference

Table 2. Breath pentane levels

\begin{tabular}{|c|c|c|c|c|}
\hline \multirow[b]{2}{*}{$\begin{array}{l}\text { Pentane } \\
(\text { nmol/L) }\end{array}$} & \multicolumn{2}{|c|}{ Means $\pm S D$} & \multicolumn{2}{|c|}{$\mathrm{P}$ values } \\
\hline & Day 0 & Day 24 & $\begin{array}{l}\text { Paired } \\
\mathrm{t} \text { test* }\end{array}$ & $\begin{array}{c}\text { Change } \\
\text { score } \\
\text { t test } \dagger\end{array}$ \\
\hline $\begin{array}{l}\text { Control } \\
\text { Treatment }\end{array}$ & $\begin{array}{l}0.20 \pm 0.19 \\
0.18 \pm 0.21\end{array}$ & $\begin{array}{l}0.46 \pm 0.36 \\
0.50 \pm 0.45\end{array}$ & $\begin{array}{l}<.05 \\
<.05\end{array}$ & NSt \\
\hline
\end{tabular}

*Paired $t$-tests are comparisons between day 0 and day 24 .

$\dagger$ Change score comparison is between the control and treatment on day 24.

$\$ N S$ indicates not significant. between baseline and day 24 individually for the control, treatment, and total sample. Within-group comparisons at the 2 sampling periods were done by independent $t$ tests. All reported $P$ values are 2 -sided comparisons, and significance was determined at $P<.05$.

\section{Results}

There were no significant differences between groups at baseline or day 24 except for initial percentage body fat (Table 1). All subjects showed a significant decrease in body weight and percentage body fat on day 24 , indicating a negative energy balance typical of military field-training exercises. ${ }^{20,21}$ The specific gravity values of both groups significantly increased over time, perhaps indicating a somewhat suboptimal fluid intake, but were still within the normal range of hydration and were not different between groups.

Paired $t$ tests show that both groups experienced a significant increase in BP concentration at day 24 compared to baseline (Table 2). However, no significance was found between the placebo and the treatment group at either time interval. Independent $t$ tests on change scores showed no significant difference.

Both groups also experienced a significant increase in the level of LPO in the serum at day 24 compared to baseline (Table 3). No significant difference existed between groups at baseline or day 24. Independent $t$ tests on change scores showed no significant difference.

Neither group experienced a significant change over time with regard to ORAC. Independent $t$ tests indicated no significant difference between groups at baseline or day 24 . The change score $P$ value for ORAC was also not significant.

The treatment group significantly increased in FRAP after the 24 days, but the control group did not. However, differences between groups were nonsignificant at either time. Taken together, this is suggestive but not conclusive evidence that the treatment increased serum antioxidant capacity.

The serum antioxidants measured included retinol, $\alpha$ - 
Table 3. Serum indicators of oxidative stress and antioxidant status*

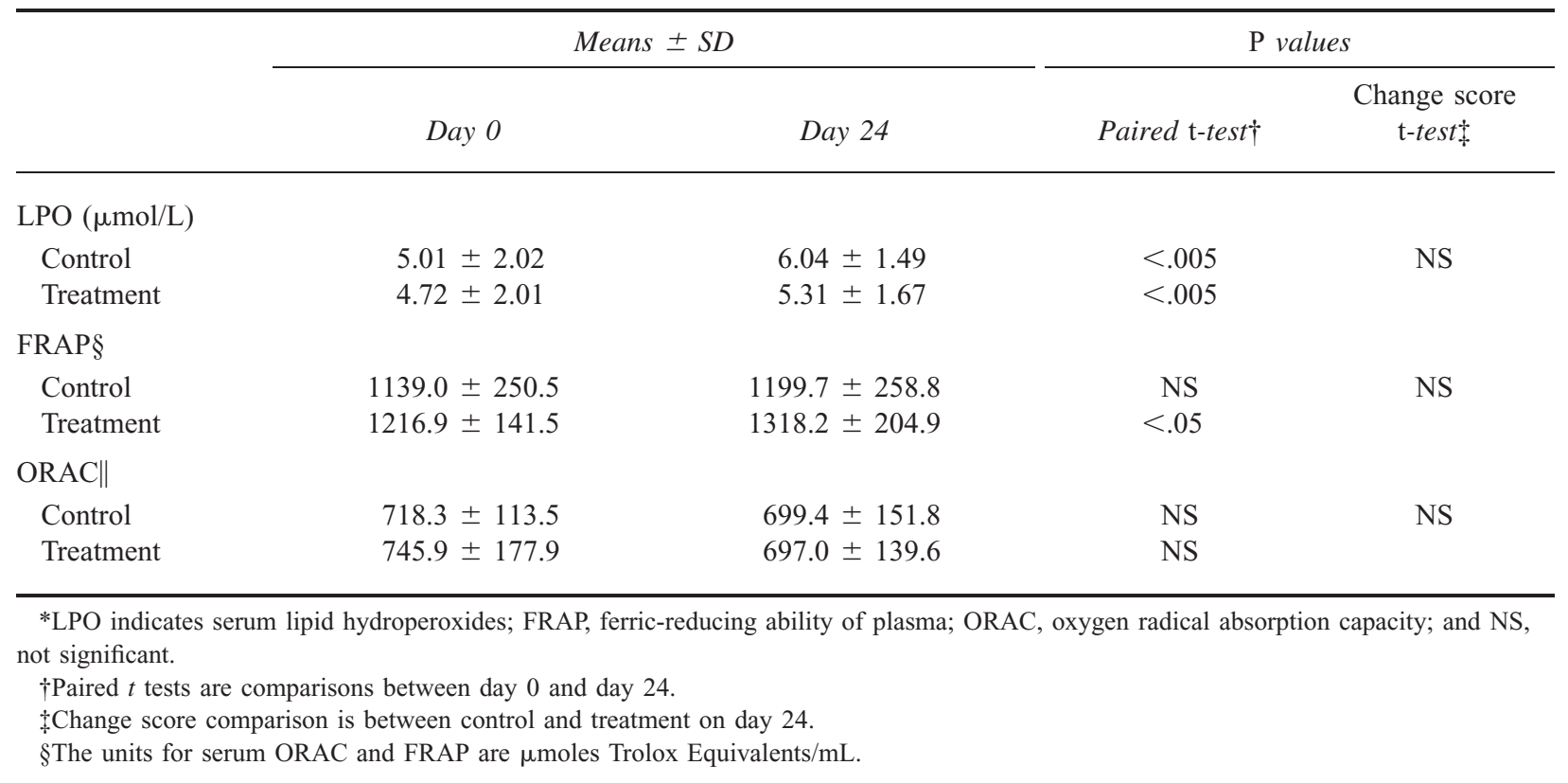

tocopherol, $\alpha$-carotene, $\beta$-carotene, lutein, lycopene, and zeaxanthin. Baseline and day 24 values of each antioxidant can be found in Table 4. A significant increase in serum levels of $\beta$-carotene and $\alpha$-tocopherol was found in the treatment group but not in the control group after the 24 days. There was also a significant difference between groups at day 24 for both $\beta$-carotene and $\alpha$-tocopherol. Retinol levels were found to be significantly lower in the control group after the 24-day period; retinol levels of the treatment group also decreased, but the decrease was not significant.

$\alpha$-Carotene, lycopene, and zeaxanthin showed significant changes for both groups after the 24-day period. $\alpha$-Carotene increased significantly in both groups, while lycopene and zeaxanthin significantly decreased for both groups.

The urine oxidative stress indices MDA, 8-OHdG, and ORAC are shown in Table 5. The repeated-measures ANOVA for MDA indicated that there was no time, group, or time by group effect. The paired $t$ tests showed no significant differences within the groups. Both the control group and the treatment group significantly increased in the amount of $8-\mathrm{OHdG}$ at day 24 compared to baseline. The repeated-measures ANOVA for $8-\mathrm{OHdG}$ showed that there was a time effect, but no group effect or time by group effect was found. The paired $t$ tests showed significantly increased 8OHdG within the groups over time. Urine ORAC was the only variable that showed a significant time by group effect.

\section{Discussion}

The results indicated that there were no significant differences between groups with respect to body weight, total body water percentage, or urine specific gravity at baseline or day 24. Overall, the sample could be considered homogeneous with regard to these characteristics, and any significance that was found in the oxidative stress indicators could be attributed to the effect of the treatment. These results also suggest that both groups were experiencing similar strenuous training and energy expenditure stresses during this 24-day period, as evident by the change in body weight, total body water percentage, and percentage body fat. Both groups significantly increased their lean body mass and total body water percentage, which was attributed to a training effect and loss of body fat. There was also a significant decrease of percentage body fat and body weight for both groups at day 24 compared to the baseline.

There was evidence that both groups experienced oxidative stress during the 24-day training period. Serum LPO, BP, and urine 8-OhdG all increased significantly over time for both groups. However, no significant differences were found between groups with regard to the amount of oxidative stress experienced.

The results of this study can be compared with 2 previous studies, which utilized the same Marine coldweather moderate-altitude field-training model. Pfeiffer et $\mathrm{al}^{20}$ found no significant antioxidant treatment effect after 14 days of field training with regard to the oxida- 
Table 4. Serum antioxidant levels

\begin{tabular}{|c|c|c|c|c|}
\hline & \multicolumn{2}{|c|}{ Means $\pm S D^{*}$} & \multicolumn{2}{|c|}{$\mathrm{P}$ values } \\
\hline & Day 0 & Day 24 & Paired $\mathrm{t}$ test $\dagger^{\dagger}$ & $\begin{array}{c}\text { Change score } \\
\mathrm{t} \text { test } t\end{array}$ \\
\hline \multicolumn{5}{|l|}{$\alpha$-Carotene } \\
\hline $\begin{array}{l}\text { Control } \\
\text { Treatment }\end{array}$ & $\begin{array}{l}0.031 \pm 0.031 \\
0.031 \pm 0.040\end{array}$ & $\begin{array}{l}0.044 \pm 0.031 \\
0.077 \pm 0.044\end{array}$ & $\begin{array}{l}<.005 \\
<.005\end{array}$ & $<.005$ \\
\hline \multicolumn{5}{|l|}{$\beta$-Carotene } \\
\hline $\begin{array}{l}\text { Control } \\
\text { Treatment }\end{array}$ & $\begin{array}{l}0.137 \pm 0.062 \\
0.127 \pm 0.046\end{array}$ & $\begin{array}{l}0.138 \pm 0.042 \\
0.456 \pm 0.017\end{array}$ & $\begin{array}{c}\mathrm{NS} \S \\
<.005\end{array}$ & $<.005$ \\
\hline \multicolumn{5}{|l|}{ Lutein } \\
\hline $\begin{array}{l}\text { Control } \\
\text { Treatment }\end{array}$ & $\begin{array}{l}0.092 \pm 0.027 \\
0.097 \pm 0.034\end{array}$ & $\begin{array}{l}0.084 \pm 0.019 \\
0.101 \pm 0.029\end{array}$ & $\begin{array}{l}\text { NS } \\
\text { NS }\end{array}$ & NS \\
\hline \multicolumn{5}{|l|}{ Lycopene } \\
\hline $\begin{array}{l}\text { Control } \\
\text { Treatment }\end{array}$ & $\begin{array}{l}0.334 \pm 0.170 \\
0.363 \pm 0.105\end{array}$ & $\begin{array}{l}0.264 \pm 0.122 \\
0.277 \pm 0.101\end{array}$ & $\begin{array}{l}<.05 \\
<.05\end{array}$ & NS \\
\hline \multicolumn{5}{|l|}{ Retinol } \\
\hline $\begin{array}{l}\text { Control } \\
\text { Treatment }\end{array}$ & $\begin{array}{l}0.488 \pm 0.092 \\
0.487 \pm 0.110\end{array}$ & $\begin{array}{l}0.405 \pm 0.091 \\
0.458 \pm 0.094\end{array}$ & $\begin{array}{c}<.005 \\
\text { NS }\end{array}$ & NS \\
\hline \multicolumn{5}{|l|}{$\alpha$-Tocopherol } \\
\hline $\begin{array}{l}\text { Control } \\
\text { Treatment }\end{array}$ & $\begin{array}{l}7.66 \pm 1.64 \\
8.64 \pm 3.81\end{array}$ & $\begin{array}{r}7.13 \pm 1.11 \\
12.12 \pm 4.80\end{array}$ & $\begin{array}{c}\text { NS } \\
<.005\end{array}$ & $<.005$ \\
\hline \multicolumn{5}{|l|}{ Zeaxanthin } \\
\hline $\begin{array}{l}\text { Control } \\
\text { Treatment }\end{array}$ & $\begin{array}{l}0.037 \pm 0.013 \\
0.039 \pm 0.012\end{array}$ & $\begin{array}{l}0.030 \pm 0.011 \\
0.033 \pm 0.012\end{array}$ & $\begin{array}{l}<.05 \\
<.05\end{array}$ & NS \\
\hline
\end{tabular}

*All units for serum antioxidants are $\mu \mathrm{g} / \mathrm{mL}$.

$\uparrow$ Paired $t$ tests are comparisons between day 0 and day 24 .

†Change score comparison is between control and treatment on day 24 .

$\S \mathrm{NS}$ indicates not significant.

tive stress index of urine 8-OHdG. However, a treatment effect was found with the oxidative stress indicator of plasma LPO. The second study by Chao et $\mathrm{al}^{21}$ used the indices of 8-OHdG, MDA, pentane, and LPO to measure oxidative stress. They found that the indices of $8-\mathrm{OHdG}$, MDA, pentane, and LPO reflected a general increased oxidative stress. However, an antioxidant treatment effect was only found with the index of BP.

On the basis of the indicators examined, the antioxidant mixture employed in the present study did not appear to be more effective than the placebo in reducing oxidative stress; however, other studies of altitude and exercise have demonstrated an antioxidant treatment effect. A study by Simon-Schnass and Pabst ${ }^{56}$ looked at the effect of stationary cycling at high altitude on the oxidative stress indicator of BP. They found that pentane increased $100 \%$ with the control group over time, but the treatment group, receiving a vitamin E supplement, remained unchanged. Alessio et $\mathrm{al}^{57}$ gave supplementation of vitamin $\mathrm{C}$ or a placebo to subjects performing 30 minutes of submaximal treadmill exercise. The oxidative stress indicator, MDA, significantly increased in the control group by $32 \%$, whereas the treatment group increased $11 \%$, which was not significant. Pfeiffer et al ${ }^{20}$ used an antioxidant supplement containing $\alpha$-tocopherol, $\beta$-carotene, vitamin $C$, selenium, and zinc and found a significant increase in LPO (30\%) in the placebo group but not the antioxidant treatment group at the end of the 14-day study.

The significant increase of serum FRAP, $\beta$-carotene, and $\alpha$-tocopherol in the treatment group suggests that the treatment group was compliant and took their antioxidant supplement. Retinol remained the same in the treatment group but significantly decreased in the control, and this may also suggest compliance. The increased levels of these antioxidants in the blood presum- 
Table 5. Urine indicators of oxidative stress and antioxidant status*

\begin{tabular}{|c|c|c|c|c|c|c|c|}
\hline & \multicolumn{3}{|c|}{ Means $\pm S D$} & \multicolumn{4}{|c|}{$\mathrm{P}$ values } \\
\hline & Day 0 & Day 12 & Day 24 & $\begin{array}{l}\text { Paired } \\
\mathrm{t} \text { test } \dagger\end{array}$ & Time effect & $\begin{array}{l}\text { Group } \\
\text { effect }\end{array}$ & $\begin{array}{c}\text { Time group } \\
\text { effect }\end{array}$ \\
\hline \multicolumn{8}{|c|}{ 8-OHdG/Creatinine (ng/mg) } \\
\hline $\begin{array}{l}\text { Control } \\
\text { Treatment }\end{array}$ & $\begin{array}{l}7.20 \pm 6.41 \\
7.68 \pm 5.82\end{array}$ & $\begin{array}{r}8.04 \pm 4.10 \\
11.41 \pm 6.56\end{array}$ & $\begin{array}{l}12.06 \pm 5.93 \\
13.18 \pm 9.21\end{array}$ & $\begin{array}{l}<.05 \\
<.005\end{array}$ & $<.005$ & NS & NS \\
\hline \multicolumn{8}{|c|}{ MDA/Creatinine $(\mu \mathrm{mol} / \mathrm{mg})$} \\
\hline $\begin{array}{l}\text { Control } \\
\text { Treatment }\end{array}$ & $\begin{array}{l}0.006 \pm 0.002 \\
0.006 \pm 0.003\end{array}$ & $\begin{array}{l}0.006 \pm 0.002 \\
0.008 \pm 0.002\end{array}$ & $\begin{array}{l}0.006 \pm 0.002 \\
0.008 \pm 0.002\end{array}$ & $\begin{array}{l}\text { NS } \\
\text { NS }\end{array}$ & NS & NS & NS \\
\hline $\begin{array}{l}\text { ORAC } \ddagger \\
\text { Control } \\
\text { Treatment }\end{array}$ & $\begin{array}{l}5.81 \pm 1.68 \\
5.32 \pm 1.96\end{array}$ & $\begin{array}{l}5.58 \pm 1.05 \\
6.90 \pm 2.46\end{array}$ & $\begin{array}{l}5.27 \pm 2.17 \\
6.46 \pm 1.82\end{array}$ & $\begin{array}{l}\text { NS } \\
\text { NS }\end{array}$ & NS & NS & $<.05$ \\
\hline
\end{tabular}

ably were made more available to the tissues, despite a lack of effect on serum antioxidant capacity (ORAC). There is some question as to the ability of the ORAC assay to reflect the antioxidant contribution of carotenoids. ${ }^{58}$ It is possible that the antioxidant capacity of the blood of the treatment group was enhanced by the carotenoids in the supplement but not detected by the ORAC assay. The significant increase in $\beta$-carotene in both groups could reflect the fact that the military diets consumed were higher in $\beta$-carotene than normal diets and that supplementation was no more effective than diet in increasing this component in the blood.

The responses of BP, 8-OHdG, and LPO generally indicated that oxidative stress did increase over the 24day period and that both groups experienced similar levels of oxidative stress. This and the 2 previous Marinebased winter-training studies ${ }^{20,21}$ all indicate that these groups of individuals are at risk for increased levels of oxidative stress that potentially could lead to oxidative damage. Although these studies agreed on exposure and response to oxidative stress under this cold-weather moderate-altitude field-training scenario, the antioxidant intervention results were not consistent. Chao et $\mathrm{al}^{21}$ showed that BP was significantly reduced in the antioxidant mixture group when compared to the placebo. The present study showed no such antioxidant supplement finding with respect to any of the indices used, except for FRAP.

One possible explanation for the lack of a treatment effect is that the military diet is relatively high in dietary antioxidants. It is estimated that military field rations are approximately $150 \%$ higher in vitamin E, $400 \%$ higher in vitamin $\mathrm{A}$, and $700 \%$ higher in vitamin $\mathrm{C}$ than the recommended daily allowance, so supplementation might not be expected to show a great effect. ${ }^{20}$ There are other possible explanations of the lack of a significant treatment effect: the optimum time at which the indices of oxidative stress should be measured to determine if a treatment effect has occurred is unknown; there may be a certain level of oxidative stress that is "constitutive" in this population, which is not responsive to further antioxidant supplementation; or the supplement may not have contained the proper amount or mixture of antioxidant nutrients to reduce the oxidative stress observed. Another perhaps more likely explanation exists - the initial antioxidant status of many of the test subjects may have been adequate; hence, an added antioxidant treatment effect would not be anticipated. ${ }^{59}$

The lack of a consistent antioxidant treatment effect in this and similar studies ${ }^{20,21}$ suggests that certain individuals may receive enough antioxidants via the diet to attenuate the increased oxidative stress associated with strenuous outdoor cold-weather training, whereas others may not. Upon examining the baseline measurement in the present study, it was seen that there was a wide variation in oxidative stress indicators among individuals in both groups at the start of the study. Such findings suggest that some individuals have better antioxidant status than others at baseline. Those individuals with low antioxidant capacity might be expected to have a significant increase in oxidative stress compared to those that had a high antioxidant capacity. To determine 
Table 6. Oxidative stress indicators in subjects with initially low or high baseline serum oxygen radical absorption capacity (ORAC) values*广

\begin{tabular}{|c|c|c|c|c|}
\hline & \multirow[b]{2}{*}{$\mathrm{n}$} & \multicolumn{2}{|c|}{ Means $\pm S D$} & \multirow{2}{*}{$\begin{array}{c}\mathrm{P} \text { values } \\
\text { Paired } \mathrm{t} \text { test }\end{array}$} \\
\hline & & Day 0 & Day 24 & \\
\hline \multicolumn{5}{|l|}{$\mathrm{LPO}(\mu \mathrm{mol} / \mathrm{L})$} \\
\hline Low ORAC & 23 & $5.09 \pm 1.88$ & $5.68 \pm 1.44$ & $.004 *$ \\
\hline High ORAC & 16 & $4.52 \pm 2.16$ & $5.64 \pm 1.87$ & $.000^{*}$ \\
\hline \multicolumn{5}{|c|}{ Pentane (nmol/L) } \\
\hline Low ORAC & 23 & $0.14 \pm 0.09$ & $0.43 \pm 0.39$ & $.003 *$ \\
\hline High ORAC & 15 & $0.25 \pm 0.32$ & $0.45 \pm 0.31$ & .150 \\
\hline \multicolumn{5}{|c|}{ 8-OHdG/Creatinine (ng/mg) } \\
\hline Low ORAC & 23 & $6.55 \pm 8.14$ & $17.25 \pm 14.57$ & $.007^{*}$ \\
\hline High ORAC & 17 & $10.04 \pm 11.07$ & $13.49 \pm 11.46$ & .367 \\
\hline \multicolumn{5}{|c|}{ MDA/Creatinine $(\mu \mathrm{mol} / \mathrm{mg})$} \\
\hline Low ORAC & 23 & $4.03 \pm 2.45$ & $7.48 \pm 3.39$ & $.000^{*}$ \\
\hline High ORAC & 17 & $5.04 \pm 3.71$ & $6.44 \pm 2.90$ & .150 \\
\hline
\end{tabular}

*Low ORAC $=$ a mean $<732.8 ;$ high ORAC $=$ a mean $>732.8$.

$\dagger$ LPO indicates serum lipid hydroperoxides; 8-OHdG, 8-hydroxy deoxyguanosine; and MDA, malondialdehyde.

if this was indeed the case, the antioxidant capacity (serum ORAC) of each subject was examined, and subjects were divided into 2 arbitrary groups, low ORAC and high ORAC. The mean ORAC for all test subjects irrespective of treatment group was determined, and those values above the mean were deemed "high" ORAC ( $n$ $=17$ ), whereas those that fell below the mean were the "low" ORAC $(n=23)$ group. Values of LPO, BP, 8$\mathrm{OHdG}$, and MDA (both expressed on a per milligram of creatinine basis) were reexamined according to this grouping to determine if there was a significant difference between low ORAC subjects and high ORAC subjects based on their antioxidant status coming into the study. Table 6 contains the information using serum ORAC as a "stratifying tool." It was found that indices of LPO, BP, MDA, and 8-OHdG all showed a significant increase in oxidative stress in the low ORAC classification. However, in the high ORAC classification, only LPO increased significantly over the 24-day period. The differences found in 3 of the 4 indices suggest that individuals with a low antioxidant capacity might benefit from an antioxidant supplement and that serum ORAC might be used as a screening tool. Serum FRAP was also examined for use as a screening tool, and similar results were found (data not shown). The data presented suggest that serum ORAC might be a useful screening tool that would be helpful in identifying those individuals at risk for oxidative stress.

To determine if the subjects classified in the low
ORAC group reacted differently to the antioxidant supplement from those using the placebo, the low serum ORAC group was separated into their original groups of treatment or control. The low ORAC contained an approximately equal number of individuals from the treatment group $(n=11)$ and control group $(n=12)$. With low ORAC subjects classified into treatment and control group LPO, BP, 8-OHdG, and MDA were reexamined to determine if there was a treatment effect between subjects based on their antioxidant status coming into the study. Table 7 contains the comparisons of indicators among individuals with initially low serum ORAC values. It was found that indices of LPO, BP, and 8-OHdG all showed an antioxidant treatment effect in the low ORAC classification. Subjects in the control group increased significantly in their values of LPO, BP, and 8OHdG, whereas the treatment group had no significant change over the 24-day period. The MDA did not show this same trend, but instead, an opposite effect was noted: the control did not change over time, but the treatment group had a significant change. The significance found in 3 of the 4 indices suggested that the antioxidant supplement was somewhat more beneficial for those individuals with low antioxidant capacity status and that serum ORAC might be useful as a screening tool. These data should be viewed with caution, however, since the number of observations is small, the treatment effect was modest, and the variability rather high. Urine ORAC and serum FRAP were also examined, and similar results 
Table 7. Oxidative stress indicators in subjects with low baseline serum oxygen radical absorption capacity (ORAC) values*†

\begin{tabular}{|c|c|c|c|c|c|}
\hline & \multirow[b]{2}{*}{$\mathrm{n}$} & \multirow[b]{2}{*}{ Group } & \multicolumn{2}{|c|}{ Means $\pm S D$} & \multirow{2}{*}{$\begin{array}{c}\mathrm{P} \text { values } \\
\text { Paired } \mathrm{t} \text { test }\end{array}$} \\
\hline & & & Day 0 & Day 24 & \\
\hline \multicolumn{6}{|l|}{ LPO $(\mu \mathrm{mol} / \mathrm{L})$} \\
\hline \multirow[t]{2}{*}{ Low ORAC } & 12 & Control & $5.23 \pm 1.95$ & $5.97 \pm 1.35$ & $<.05$ \\
\hline & 11 & Treatment & $4.94 \pm 1.88$ & $5.37 \pm 1.52$ & NS \\
\hline \multicolumn{6}{|c|}{ Pentane (nmol/L) } \\
\hline \multirow[t]{2}{*}{ Low ORAC } & 12 & Control & $0.14 \pm 0.10$ & $0.39 \pm 0.27$ & $<.005$ \\
\hline & 11 & Treatment & $0.14 \pm 0.08$ & $0.47 \pm 0.50$ & NS \\
\hline \multicolumn{6}{|c|}{ 8-OHdG/Creatinine (ng/mg) } \\
\hline \multirow[t]{2}{*}{ Low ORAC } & 12 & Control & $6.19 \pm 5.86$ & $13.61 \pm 5.69$ & $<.05$ \\
\hline & 11 & Treatment & $7.60 \pm 5.64$ & $12.71 \pm 10.54$ & NS \\
\hline \multicolumn{6}{|c|}{ MDA/Creatinine $(\mu \mathrm{mol} / \mathrm{mg})$} \\
\hline \multirow[t]{2}{*}{ Low ORAC } & 12 & Control & $0.007 \pm 0.002$ & $0.006 \pm 0.001$ & NS \\
\hline & 11 & Treatment & $0.006 \pm 0.003$ & $0.008 \pm 0.003$ & $<.05$ \\
\hline
\end{tabular}

*Low ORAC $=$ a mean $<732.8 ;$ high ORAC $=$ a mean $>732.8$.

$\dagger$ LPO indicates serum lipid hydroperoxides; 8-OHdG, 8-hydroxy deoxyguanosine; MDA, malondialdehyde; and NS, not significant.

were found (data not shown). Although the data presented might suggest that serum ORAC could be used as a screening tool and would be helpful in targeting those individuals at risk for oxidative stress, it should be noted that the resultant sample size was reduced when stratified by initial ORAC values. A power analysis based on predicted response and indicator variability indicates that a sample size of 14 was needed at the beginning of the study for each group, and the sample size for this comparison was 11 and 12 . Whether or not serum ORAC could be used as a reliable screening tool to determine those individuals at greater risk for oxidative stress will require further research with a larger number of test subjects.

The results of this study indicate that people who work or recreate at even a moderate altitude may be at risk for oxidative stress as a result of free radical production. A 24-day supplementation of a mixture of antioxidants did not reduce the exercise-induced oxidative stress associated with cold-weather military training at moderate altitudes, compared to the placebo, but the results did provide some indication that individuals with low initial antioxidant status may derive some benefit from such a supplement.

\section{Acknowledgment}

The authors would like to acknowledge the assistance of Mr Greg Stoddard in the statistical analysis of this study.

\section{References}

1. Frei B. Reactive oxygen species and antioxidant vitamins: mechanisms of action. Am J Med. 1994;97:5S-13S; discussion: 22S-28S.

2. Kehrer JB, Smith CV. Free radicals in biology: sources, reactivates and roles in the etiology of human diseases. In: Frei B, ed. Natural Antioxidants in Human Health and Disease. Orlando, FL: Academic Press; 1994:25-62.

3. Halliwell B, Gutteridge JM. Free Radicals in Biology and Medicine. 2nd ed. New York, NY: Oxford University Press; 1993.

4. Ames BN, Shigenaga MK, Hagen TM. Oxidants, antioxidants, and the degenerative diseases of aging. Proc Natl Acad Sci U S A. 1993;90:7915-7922.

5. Jenkins RR, Goldfarb A. Introduction: oxidant stress, aging, and exercise. Med Sci Sports Exerc. 1993;25:210212.

6. Loft S, Poulsen HE. Cancer risk and oxidative DNA damage in man. J Mol Med. 1996;74:297-312.

7. Ji LL. Antioxidant enzyme response to exercise and aging. Med Sci Sports Exerc. 1993;25:225-231.

8. Florence TM. The role of free radicals in disease. Aust $N$ Z J Prev. 1995;13:8-14.

9. Halliwell B. Reactive oxygen species in living systems: source, biochemistry, and role in human disease. Am J Med. 1991;91(suppl 3C):14S-22S.

10. Haramaki N, Packer L. Oxidative stress indices in exercise. In: Sen CK, Packer L, Hanninen O, eds. New York, NY: Elsevier Science; 1994:77-88.

11. Pyne DB. Exercise-induced muscle damage and inflammation: a review. Aust J Sci Med Sports. 1994;26:49-58. 
12. Singh VN. A current perspective on nutrition and exercise. J Nutr. 1992;122:760-765.

13. Jenkins RR. Free radical chemistry: relationship to exercise. Sports Med. 1988;5:156-170.

14. Jones DP. The role of oxygen concentrations in oxidative stress: hypoxic and hyperoxic models. In: Oxidative Stress. London: Academic Press; 1985:151-189.

15. Witt EH, Reznich AZ, Viguie CA, Starke RP, Packer L. Exercise, oxidative damage and effects of antioxidants manipulation. J Nutr. 1992;122:766-773.

16. Alessio HM. Exercise-induced oxidative stress. Med Sci Sports Exerc. 1993;25:218-224.

17. Kripke ML. Immunology and photocarcinogenesis. J Am Acad Dermatol. 1986;14:149-155.

18. Ghosh R, Bhaumik G. Supernatant medium from UV-irradiated cells influences the cytotoxicity and mutagenicity of V79 cells. Mutat Res. 1995;335:129-135.

19. Askew EW. Environmental and physical stress and nutrient requirements. Am J Clin Nutr. 1995;61:631S-637S.

20. Pfeiffer JM, Askew EW, Roberts DE, et al. Effect of antioxidant supplementation on urine and blood markers of oxidative stress during extended moderate-altitude training. Wilderness Environ Med. 1999;10:66-74.

21. Chao W, Askew EW, Roberts DE, Wood SM, Perkins JB. Oxidative stress in human during work at moderate altitude. J Nutr. 1999;129:2009-2012.

22. Bailey DM, Davies B, Young IS, Hullin DA, Seddon PS. A potential role for free radical-mediated skeletal muscle soreness in the pathophysiology of acute mountain sickness. Aviat Space Environ Med. 2001;6:513-521.

23. Bailey DM, Davies B. Acute mountain sickness; prophylactic benefits of antioxidant vitamin supplementation at high altitude. High Altitude Med Biol. 2001;2:21-29.

24. Simon-Schnass I. Oxidative stress at high altitudes and effects of vitamin E. In: Marriott BM, Carlson SJ, eds. Nutritional Needs in Cold and in High Altitude Environments. Washington, DC: National Academy Press; 1996: 393-418.

25. Vasankari TJ, Kujala UM, Rusko H, Sarna S, Ahotupa M. The effect of endurance exercise at moderate altitude on serum lipid peroxidation and antioxidant functions in humans. Eur J Appl Physiol. 1997;75:396-399.

26. Subudhi AW, Davis SL, Kipp RW, Askew EW. Antioxidant status and oxidative stress in elite alpine ski racers. Int J Sports Med. 2001;11:32-41.

27. Jacob RA, Burri BJ. Oxidative damage and defense. Am J Clin Nutr. 1996;63:985S-990S.

28. Papas AM. Determinants of antioxidant status in humans. Lipids. 1996;31(suppl):S77-S82.

29. Goldfarb AH. Antioxidants: role of supplementation to prevent exercise-induced oxidative stress. Med Sci Sports Exerc. 1993;25:232-236.

30. Kanter MM, Nolte La, Holloszy JO. Effects of an antioxidant vitamin mixture on lipid peroxidation at rest and postexercise. J Appl Physiol. 1993;74:965-969.

31. Diplock AT, Lucy JA. The biochemical models of action of vitamin E and selenium: a hypothesis. FEBS Lett. 1973; 29:205-211.

32. Gohil K, Packer L, Brooks GA, Terblanche SE. Vitamin E deficiency and vitamin C supplements: exercise and mitochondrial oxidation. J Appl Physiol. 1986;60:19861991.

33. Olson JA, Krinsky NI. Introduction: the colorful, fascinating world of the carotenoids: important physiologic modulators. FASEB J. 1995;15:1547-1550.

34. Rice-Evens CA, Miller NJ. Antioxidant activities flavonoids as bioactive components of food. Biochem Soc Trans. 1996;24:790-794.

35. Sies H, Stahl W. Vitamin E and C, Beta-carotene, and other carotenoids as antioxidants. Am J Clin Nutr. 1995; 62(suppl 6):1315S-1321S.

36. Krinsky NI. Actions of carotenoids in biological systems. Annu Rev Nutr. 1993;63:93-121.

37. Rock LR, Jacob RA, Bowen PE. Update on the biological characteristics of the antioxidant micronutrients: vitamin C, vitamin E, and the carotenoids. J Am Diet Assoc. 1996; 96:693-702.

38. Schalch W. Carotenoids in the retina: a review of their possible role in preventing of limiting damage caused by light and oxygen. Free Rad Aging. 1992;280-298.

39. Mitscher LA, Jung M, Shankel D, Dou JH, Steele L, Pillai SP. Chemoprotection: a review of the potential therapeutic antioxidant properties of green tea (Camellia sinensis) and certain of its constituents. Med Res Rev. 1997;4:327-365.

40. Packer L, Witt EH, Tritschler H. Alpha-lipoic acid as a biological antioxidant [review]. Free Rad Biol Med. 1995; 2:227-250.

41. Rao AV, Agarwal S. Bioavailability and in vivo antioxidant properties of lycopene from tomato products and their possible role in the prevention of cancer. Nutr Cancer. 1998;31:199-203.

42. Stahl W, Junghans A, de Boer B, Driomina ES, Briviba K, Sies H. Carotenoid mixtures protect multilamellar liposomes against oxidative damage: synergistic effects of lycopene and lutein. FEBS Lett. 1998;427:305-308.

43. Palozza P, Krinsky NI. Beta-carotene and alpha-tocopherol are synergistic antioxidants. Arch Biochem Biophys. 1992; 297:184-187.

44. Britton G. Structure and properties of carotenoids in relation to function. FASEB J. 1995;9:1551-1558.

45. Durnin JV, Wormsley J. Body fat assessed from total body density and its estimation from skinfold thickness: measurements on 481 men and women aged 16 to 72 years. Br J Nutr. 1974;32:77-96.

46. Ohishi N, Ohkawa H, Miike A, Tatano T, Yagi K. A new assay method for lipid peroxides using a methylene blue derivative. Biochem Int. 1985;10:205-211.

47. Stacewicz-Sapuntakis M, Bowen PE, Kikendall JW, Burgess M. Simultaneous determination of serum retinol and various carotenoids: their distribution in middle aged men and women. J Micronutr Anal. 1987;3:27-45. 
48. Cao G, Verdon CP, Wu AHB, Wang H, Prior RL. Automated assay of oxygen radical capacity with the COBAS FARA II. Clin Chem. 1995;41:1738-1744.

49. Benzie IFF, Strain JJ. The ferric reducing ability of plasma (FRAP) as a measure of "antioxidant power": the FRAP assay. Anal Biochem. 1996;239:70-76.

50. Shigenaga MK, Park JW, Cundy KC, Gimeno CJ, Ames BN. In vivo oxidative DNA damage: measurement of 8-hydroxy-2-deoxyguanosine in DNA and urine by high-performance liquid chromatography with electrical detection. Methods Enzymol. 1990;186:521-530.

51. Shigenaga MK, Ames BN. Assays for 8-hydroxy-2-deoxyguanosine: a biomarker of in vivo oxidative DNA damage. Free Rad Biol Med. 1991;10:211-216.

52. Janero DR. Malonaldehyde and thiobarituric acid-reactivity as diagnostic indices of lipid peroxidation and peroxidative tissue injury. Free Rad Biol Med. 1990;9: 515-540.
53. Bowers L, Wong E. Kinetic serum creatinine assays. II. A critical evaluation and review. Clin Chem. 1980;26:555.

54. Zarling EJ, Clapper M. Technique for gas-chromatographic measurement of volatile alkanes from single-breath samples. Clin Chem. 1987;33:140-141.

55. Pocock SJ. Clinical trails: a practical approach. New York, NY: John Wiley; 1983:231-233.

56. Simon-Schnass J, Pabst H. Influence of vitamin E on physical performance. Int J Vitam Nutr Res. 1988;38:49-54.

57. Alessio HM, Goldfarb AH, Cao G. Exercise-induced oxidative stress before and after vitamin $\mathrm{C}$ supplementation. Int J Sports Nutr. 1997;7:1-9.

58. Schmidt M, Askew EW, Prior RL, Roberts DE, Ensign WY, Hesslink RE Jr. Correspondence between serum antioxidant capacity and oxidative stress indicators in blood, breath and urine [abstract]. FASEB J. 2001;15:A609.

59. Halliwell B. Establishing the significance and optimal intake of dietary antioxidants: the biomarker concept. Nutr Rev. 1999;57:104-113. 